\title{
Effects of Spatial Intelligence-based Instruction on Learning Pictorial Idiomatic Expressions in an EFL Context
}

\author{
Mehdi Solhi Andarab \\ English Preparatory School, Bahcesehir University \\ Istanbul, Turkey \\ E-mail: solhi.mehdi@gmail.com
}

Received: 26-09- 2014

Published: 01-05- 2015
Accepted: 15-12- 2014

doi:10.7575/aiac.ijalel.v.4n.3p.109
Advance Access Published: December 2014

URL: http://dx.doi.org/10.7575/aiac.ijalel.v.4n.3p.109

\begin{abstract}
In this study, at the outset, the effect of spatial intelligence-based instruction on learning pictorial idioms in an EFL context was investigated. Then, an attempt was made to find the possible difference between male and female learners' spatial intelligence with regard to the learning of pictorial idioms. To this end, 50 female and 50male EFL students were randomly selected. After distributing a questionnaire, the participants with high spatial intelligence were assigned to the experimental group while the participants with lower intelligence profile were assigned into the control group. The same procedure was followed with regard to the male participants. The number of the participants was slightly high. Therefore, they were divided into several subgroups. The both groups showed to be homogenous concerning their knowledge of the English idioms. Then, the idioms taught to the both control (the learners with low spatial intelligence profile) and the experimental groups (the learners with high spatial intelligence profile) were pictorial spatial intelligence-based. The treatment continued for approximately 3 months. An independent samples t-test applied on the scores achieved from a posttest showed a significant difference between the control and the experimental groups of the both male and female participants in apprehending the meaning of the English idioms. However, the results obtained from the two-way ANOVA conducted on the scores earned from the posttest showed a significant difference between the male and female participants' intelligence profile in learning the pictorial idioms. As a result, the spatial intelligence-based instruction of English idioms proved to be highly beneficial when teaching idioms.
\end{abstract}

Keywords: Spatial Intelligence-based Instruction, Pictorial Idioms

\section{Introduction}

Traditionally, the interpretation of the learners' intelligences was based on the Intelligent Quotient (IQ) test developed by Alfred Binet, a French psychologist. Binet was asked to produce a set of test items that was supposed to predict an individual's achievement or deficiency in school. Intelligence was considered to be quantifiable. However, in recent years, there has been a great change in the interpretation and application of the intelligence. The most dominant and controversial contribution to the interpretation and application of intelligence was that proposed by Gardner (1993). Gardner's Multiple Intelligence Theory is comprised of eight native intelligences which may vary from one culture to the next. Following Gardner's notion, the traditional and mono-dimensional views of intelligence including a narrow range of abilities (Christison \& Kennedy, 1999) have been replaced by the most recent views of intelligence which contain a wide range of abilities. Gardner (1993) proposes the existence of eight separate human intelligences, namely, Linguistic, Logical, Spatial, Bodily-kinesthetic, Musical, Interpersonal, Intrapersonal, and Naturalist Intelligences. Gardner (1999) clarifies that strengths in certain intelligences also influence other intelligences, indicating a dependency of these capabilities upon one another. Gardner (1993) believes that none of the intelligences has priority over another. His theory is not meant to categorize students into groupings. Everyone has the ability to develop all eight intelligences to a higher extent if given the appropriate environment, stimulation and encouragement. Later, in his theory, Gardner has considered the possibility of additional intelligences, including existential and emotional intelligences which have not been included in Multiple Intelligence Theory yet.

Recently, the utilization of the multiple intelligences has influenced the language pedagogy and the language skills/subskills. Hence, the attention has been turned to Multiple Intelligences to be adopted and used in language teaching programs. According to Dillon (2006), methods used in college English classroom are effective in improving linguistic abilities of the learners but it is obvious that learners' potentials cannot be constrained to the mono-dimensional one, linguistic intelligence as he means. The learners' potentials are multifaceted and multi-dimensional. She points out that not only the linguistic ability of the learner, but also his/her other potentials should also be focused upon. Kallenbach and Veins (2001) similarly state that the introduction of the multiple intelligences has aroused the enthusiasm of the educational community in favor of matching MI findings with the pedagogical realities. With its inclination toward understanding the shape, color, line, and form the role of spatial intelligence, one of the Gardner's intelligences, has always been significant in learning a language (Christison, 1999). Armstrong $(2000,2003)$ claims that providing the learners with visual mapping activities and encouraging students to create charts, bulletin boards, establishing class 
atmosphere in which the learners can draw pictures, watch pictures on TV and voice their opinion about the pictures are the characteristics of this intelligence. He suggests using graphs, and diagrams, visualization, photography, videos/DVDs, slides and movies, visual puzzles, mind mapping, visual pattern seeking, color cueing activities, and so on that could be used to nurture the spatial intelligence of the learners.

As evident, many scholars argue in favor of integrating the multiple intelligences theory in the materials. However, with regard to the relationship between MI theory and language skills/ sub-skills, there lie some gaps in need of exploration (Christison, 1999; Armstrong, 2000, 2003).The idiomatic expressions, as an inseparable and important part of a language, have always been one of the most difficult parts of a language to learn. This is due to the fact that these expressions cannot be literally understood. He adds that every language learner is expected to develop competence in them since they are employed by native speakers in spoken and written modes (as cited in Hussein et al., 2000). According to Hussein et al. (2000), the idioms are difficult to learn and teach for many reasons. The main reason, McPartland (1981) believes, is that idioms are not literal and they do not mean what they say. McPatland (1981) mentions that the easiest idioms are those which have exact counterparts in the learner's mother tongue, and the most difficult ones are those which have no counterparts and whose meaning cannot be obtained from the meaning of their constituents. According to Irujo (1993), second language learners usually have difficulty using English idioms. Therefore they prefer to avoid them altogether. She believes that it maybe as a result of transferring part of an idiom in their first language to an English idiom. However, even the most advanced learners tend to avoid using idioms because idioms are not to be interpreted literally and they are considered by learners to be language specific and therefore not transferable to a second language. Whereas some propose (e.g., Nelson, 1992) that the second language learners understand idioms by directly comprehending of the figurative meanings, a group of scholars claims that the language learners first literally grasp idioms, then they comprehend the figurative meanings (Cieslicka, 2006). Underlining the importance of the metaphorical competence, Kecskes (2002, as cited in Cieslicka, 2006) points out that the lack of the competence in the second language, can lead the learners to use their first language conceptual system and eventually depend on the literal meanings of the figurative utterance when processing the figurative phrases. Cieslicka (2006) states that since the second language learners face the literal meanings of a language long before their figurative meanings, it worth underlying that the literal meanings of the figurative phrases hold priority over figurative ones when processing them.

Whereas some propose that L2 learners comprehend idioms by direct retrieval of their figurative meanings (Nelson, 1992), others claims that L2 learners first process idioms literally, then access their figurative meanings (Cieslicka, 2006). Kecskes (2002, as cited in Cieslicka, 2006) proposes that due to the lack of metaphorical competence in L2, second language users are more likely to rely on literal meanings of figurative utterance and on their L1 conceptual system when producing and comprehending figurative phrases. Matlock and Heredia (2002, as cited in Cieslicka, 2006) suggest that the role of literal and figurative meanings in the processing of L2 idioms will be determined by the L2 learner's proficiency in the language. Accordingly, they have proposed that non-experienced (beginner) second language learners must first establish direct connections between literal and non-literal meanings of figurative expressions. They believe that idiom comprehension at early stages of L2 learning as consisting of three stages: firstly, an L2 idiomatic expression is translated literally into L1. Next, the learner accesses the literal meaning of the expression and tries to make sense of it. Finally, in the third stage, the figurative meaning is accessed. They add that at more advanced stages of L2 learning, the L2 speaker may process figurative expressions in the same manner as a native speaker, without having to access their literal meanings first. Furthermore, Cieslicka (2006) states that since L2 learners become familiar with literal meanings of second language lexical items long before they encounter their figurative meanings in fixed phrases, it seems reasonable to assume that literal meanings have priority over figurative ones in the course of processing idiomatic phrases by second language learners.

Theoretically, Spatial Intelligence-Based Instruction (SIBI) refers to the creation of the materials which are based on the mental images along with visual perception of the environment. It can be developed through experiences in the graphic arts, sharpening observation skills and exercises in imagery and active imagination. As a result, through establishing images in the materials and consequently in the mind of the learners, teaching and learning processes can be facilitated. Operationally, it embodies a set of picture-based inputs teaching which is likely to perpetuate learning a language. Hence, manipulating and teaching the materials through the characteristics of Spatial Intelligence, e.g. color, size, shape and so on, is called Spatial Intelligence-based Instruction.

In fact, the majority of the idiomatic expressions can be grouped into various categories, such as fruit, numbers, animals, body whose meanings can only be literally understood. These idioms are shown via the pictures entitled pictorial idioms. As mentioned before, comprehending the pictures is one of the main features of the spatial intelligence. Many of research studies conducted on MI Theory were based on the linguistic intelligence. As the literature review indicates, it seems that no research has been done to measure the importance of the spatial intelligence on idiomatic expressions or foreign language. Accordingly, in this study, an attempt was made to bridge an unexplored gap between spatial intelligence and learning pictorial idioms. Accordingly, at the outset, the effect of spatial intelligence-based instruction on Iranian EFL learners' learning of pictorial idiomatic expressions was investigated. Then, the difference between the male and female EFL learners' spatial intelligence with regard to the learning of pictorial idiomatic expressions was studied. 


\section{Method}

\subsection{Participants}

The subjects participating in this research were 100 pre-intermediate EFL learners who had registered in a language institute. The participants consisted of 50 female and 50 male learners ranging from 13 to 21 years old. They were learning English as a foreign language in communicative-oriented classes. First, through a questionnaire adapted from Saeidi (2006) and Halley (2004), female learners' spatial intelligence was measured. Then, they were assigned to an experimental group and a control group. Participants who had higher spatial intelligence profile were included in the experimental group and the ones with low intelligence were included in the control group. The same procedure was conducted to the group of male learners. Two language teachers were in charge of teaching pictorial idioms on the basis of the objectives of the present study. The learners were unfamiliar to this new approach of learning idioms. Because this approach to teach idiomatic expressions was fairly new to them. Most of the materials on the market are not colorful and not categorized according to the topic. For the reason that the pictorial idioms presented to them were colorful and they were based on the topics and the pictures were inserted into the idioms, they had never encountered those kinds of pictorial idioms until then. In order to motivate the learners to participate, first of all, the manuscripts were distributed to the learners free of charge and second of all everyday idiomatic expressions running in close parallel with their interests were included as the content of the treatment. Their interests were explored through a questionnaire. Students were told that they would take part in a survey to know about their intelligence profile. So, they got interested to find out whether they were intelligent or not. After assigning the test, nearly all the participants asked for their intelligence profile. Some of them even requested additional questionnaires to measure their own relatives' intelligence profiles. It was a new experience for them. Even their parents showed some interest in their children's intelligence profile. As a result, all participants enthusiastically took part in the intelligence quiz.

\subsection{Materials}

Two questionnaires were used. At first, an adapted questionnaire used by Halley (2004) and Saeidi (2006) was applied for the specification of the spatial intelligence profile of the learners. The questionnaire served the purpose of specifying spatial intelligence of the participants in order to gain a perception of the weaknesses and strengths of the subjects. There were 40 items in this questionnaire, five items for each of the eight intelligences. The participants were supposed to rank 0,1 , or 2 on the questionnaire for each item. At the end, they were added to reach a single score. The final scores ranging from 10 to 7 were considered high, the scores ranging from 6 to 4 were considered moderate and the scores ranging from 3 to 0 were considered low spatial intelligence profile. The individuals whose scores were 5 or higher than 5 were included in the experimental group and the ones lower than 5 were included in the control group.

The second questionnaire was introduced to find out the participants' interest in a certain group of idioms (e.g., animal, body, number, and fruit idioms) which were going to be taught. The Alpha Cronbach reliability index measured for the first questionnaires was. 73 and that of the second questionnaire was .68. The results indicated that most of the learners were fascinated by animal idioms and not many individuals were interested in number idioms. Due to the fact that their interest played an important role, the main attention was paid to the animal idioms.

A pre-test, consisting of twenty idiom questions with the total score of 20 extracted from an unpublished book, prepared by the researcher, was administered in order to classify the learners' former idiomatic knowledge. The time allotted to the learners to answer the questions was 20 minutes. The pre-test served the purpose of selecting a homogeneous group of students for the treatment. The reliability of the pre-test was estimated at 0.68 with use of Alpha Cronbach.

In undertaking the present research, a treatment was undertaken to observe its result on the posttest. The content of the treatment and the tests were extracted from an idiomatic book, entitled Pictorial Idioms and Slang of English Language.

To arrive at the purpose of the study, a post-test including twenty idiomatic questions which were presented as multiple choice questions was administered. Before administering the test, a treatment, the content of which was picture-based and was extracted from the idiomatic book, was undertaken. To this end and in order to observe the numerical scores resulting from the post-test followed by the picture-based treatment, the scores of the two tests were compared to examine the possible significant difference between them and to observe the intended improvement. The reliability of post-test was estimated at 0.75 .

\subsection{Procedures}

To address the first research question, 50 female and 50male students who were studying students English in the preintermediate level were randomly selected. Then, the female participants with high spatial intelligence profile were included in the experimental group and those with low spatial intelligence were included in the control group. The same procedure was followed with regard to the male participants. The participants were aging between 13 to 21 years old and studying English in the same level. Because of the number of the students, they were divided into several subgroups. The content of pre-test was extracted from the idiomatic book. They were multiple choice questions. The learners were supposed to answer the questions in 20 minutes. Before administering the pretest, the learners were informed that it could be normal if they would not even be able to answer to all of the questions. To reduce their stress and anxiety, they were told that it should not be considered as an exam and if they cannot answer the questions, it could be useful to them to discover the area that they are not good at.

To start the preliminary study, at the outset, a pilot test was conducted. In so doing, 40 pictorial idioms were taught to a sample which represented the population. The pilot test was the try-out of materials before administering to the main participants to determine their suitability and effectiveness. 
At first, the questionnaires were assigned to the learners and they were expected to rate them from 0 to 2 . It took about 25 minutes to answer both of the questionnaires. There were 40 items in the first questionnaire and 1 item in the second one. In order to make sure whether students were well-directed or not, the items were translated into Persian and the spatial intelligence of the learners in both groups was specified using the same questionnaire.

Then, the pretest was given to all groups to examine learners' former idiomatic knowledge; next, a oneway ANOVA was conducted between the female and male learners' pretest scores in both control and experimental groups and because the difference (.97) between them was not statistically significant, the research was conducted. Then, spatial intelligence-based pictorial idioms were taught to the both experimental and control groups (both females and males). The treatment was spatial intelligence-based. Hence, an attempt was made to insert pictures into the idiomatic expressions. The pictures were substituted for the written words, for example a picture of a cat was substituted for the word 'cat' in an expression of 'like a cat on hot bricks'. The treatment continued approximately for 3 months. The procedure conduced to the control group was different. The idioms taught to the learners in the control group were ordinary idioms and they were not based on spatial intelligence.

There are a lot of research studies focusing on learning idioms or applying Gardner's (1993) Multiple Intelligences Theory separately. These studies have had considerable contributions to teaching and learning processes but less attention has been paid to the possible effects of Spatial Intelligence on learning pictorial idioms of English language. Discovering the learners' strong and weak intelligences in the learning process enables us to shape and reshape our curricula and syllabus and adopt teaching strategies congruent with their learning preferences. To the best knowledge of the researcher, no research has been conducted to explore the above-mentioned effect.

\section{Results}

To address the first research question, the scores obtained through the pretest, posttest and the questionnaires were analyzed by using the SPSS software version 12.0. At first, to be sure that there is not a significant difference between the pretest score of the control group and that of the experimental group, a oneway analysis of variance between the two levels was conducted. As the results of the ANOVA run for the pre-test indicates (Table 1), there was no significant difference between the groups in the pretest $F(3,96)=2.16, p>.05$. Hence, the researcher conducted a study to investigate the effect of the spatial intelligence-based instruction on learning pictorial idioms.

Table 1. One-Way ANOVA for the Experimental Group

\begin{tabular}{llllll}
\hline & SS & df & MS & F-value & Sig \\
\hline Between group & 59.99 & 3 & 19.99 & 2.167 & .097 \\
Within groups & 885.80 & 96 & 9.22 & & \\
Total & 945.79 & 99 & & & \\
\hline
\end{tabular}

Then, an independent samples t-test was applied to examine the possible significant difference between the two groups of the participants in order to compare the data obtained from the posttest of the control group with that of the experimental group of the female learners. The descriptive statistics in Table 2 indicated that the experimental group had higher mean $(\mathrm{M}=18.34)$ in comparison to the control group $(\mathrm{M}=15.88)$ on the posttest. The data presented in Table 3 indicate that there was a significant difference in scores for the posttest of the control group $(\mathrm{M}=15.88, \mathrm{SD}=$ $2.02)$ and that of the experimental group $(\mathrm{M}=18.34, \mathrm{SD}=1.49), t(48)=-4.896, p<.001$

Table 2. Descriptive Statistics for the Posttest of the Females

\begin{tabular}{lccc}
\hline Group & $\mathrm{N}$ & Mean & SD \\
\hline Experimental & 32 & 18.34 & 1.49 \\
Control & 18 & 15.88 & 2.02 \\
\hline
\end{tabular}

Table 3. T-Test Results Between the Control and the Experimental Groups' Posttests of the Females

\begin{tabular}{|c|c|c|c|c|c|c|}
\hline & $\mathrm{F}$ & Sig. & $\mathrm{t}$ & $\mathrm{df}$ & Sig. (2-tailed) & Mean difference \\
\hline Equal variances & 1.43 & .23 & -4.89 & 48 & .000 & -2.45 \\
\hline \multicolumn{7}{|l|}{ Assumed } \\
\hline Equal variances & & & & -4.49 & 27.58 & -2.45 \\
\hline
\end{tabular}


Then, an independent samples-test was conducted to compare the posttest of the control group and that of the experimental in the male learners. The descriptive statistics for the two groups indicated in Table 4 showed that the experimental group had lower mean $(M=18.07)$ in comparison to the control group $(M=15.81)$ on the posttest. According to Table 5, there was a significant difference between the mean score of the control group $(\mathrm{M}=15.81, \mathrm{SD}=$ $2.53)$ and that of the experimental group $(\mathrm{M}=18.07, \mathrm{SD}=1.43, t(48)=-3.72, p<.001$, as indicated in Table3.

Table 4.Descriptive Statistics for the Posttest of the Males

\begin{tabular}{llll}
\hline Group & $\mathrm{N}$ & Mean & SD \\
\hline Experimental & 28 & 18.07 & 1.43 \\
Control & 22 & 15.81 & 2.53 \\
\hline
\end{tabular}

Table 5. T-Test between the Posttests of the Control and the Experimental Groups of the Males

\begin{tabular}{lllllll}
\hline & $\mathrm{F}$ & Sig. & $\mathrm{t}$ & $\mathrm{df}$ & Sig. (2-tailed) & Mean difference \\
\hline Equal variances & 4.92 & .031 & -3.96 & 48 & .000 & -2.25 \\
$\begin{array}{l}\text { Assumed } \\
\text { Equal variances }\end{array}$ & & & -3.72 & 3.38 & .001 & -2.25 \\
not assumed & & & & & & \\
\hline
\end{tabular}

Consequently, to investigate the second research question, a $2 \times 3$ between groups factorial ANOVA was conducted to evaluate the effects of spatial intelligence-based instruction on learning pictorial idioms. Hence, the posttest of the control groups and that of the experimental groups of the males and females were compared. The results achieved from the two-way ANOVA run on the data and presented in Table 6 and 7 indicate that there is not a significant difference in scores between the male and female learners' intelligence in learning pictorial idioms $(F=.20, p=.65)$. The main difference between these two levels suggests that there is not any considerable effect on learning pictorial idioms. On the contrary, through paying attention to the groups effect (Table 7), we can observe that the main effect of groups is statistically significant $(F=38.37, p<.001)$ and there is significant difference between the control and the experimental groups.

Table 6. Descriptive Statistics for the Effects of Spatial Intelligence with Regard to Sex

\begin{tabular}{lllll}
\hline Sex & Group & $\mathrm{N}$ & Mean & SD \\
\hline \multirow{2}{*}{ Female } & Control & 18 & 15.88 & 2.02 \\
& Experimental & 32 & 18.34 & 1.49 \\
& Total & 50 & 17.46 & 2.06 \\
\hline \multirow{2}{*}{ Male } & Control & 22 & 15.81 & 2.53 \\
& Experimental & 28 & 18.07 & 1.43 \\
& Total & 50 & 17.08 & 2.27 \\
\hline \multirow{2}{*}{ Total } & Control & 40 & 15.85 & 2.29 \\
& Experimental & 60 & 18.21 & 1.46 \\
& Total & 100 & 17.27 & 2.16 \\
\hline
\end{tabular}

Table 7. Two-Way ANOVA for the Effects of Spatial Intelligence on Learning Spatial Intelligence-Based Instruction Source

\begin{tabular}{lllll}
\hline & df & Mean & F & Sig \\
Sex & 1 & .701 & .20 & .65 \\
Group & 1 & 131.96 & 38.37 & .000 \\
Sex*Group & 1 & .242 & .07 & .791 \\
Error & 96 & 3.43 & & \\
Total & 100 & & & \\
Correlated total & 99 & & \\
\hline
\end{tabular}




\section{Discussion}

Many researchers have made an attempt to include it in the process of language learning. The popularity of MI in education is mainly due to the fact that it considers an individual as a main role player in the act of teaching and learning (Armstrong, 2000, 2003; Christison \& Kennedy, 1999; Gardner, 1991). The implication of MI to the individualized educational program has already been clarified by Gardner (1991) and Christison and Kennedy (1999) who hold the view that the nurturance of the intelligences which are dominant in the classroom and are associated with the interests, styles, strategies and techniques of the individual learners can possibly yield the most productive result in the pedagogical context.

In this study, one of intelligences of Gardner's Theory, spatial intelligence, was taken into account. Spatial Intelligence, as mentioned earlier, includes the ability of an individual to understand the world through the forms, shapes, etc. The result obtained in this study showed that teaching idiomatic expressions which were based on spatial intelligence was statistically significant for male and female learners who had high spatial intelligence profiles. These findings give further support to Armstrong's (2004) claim that replacing pictures with the words in the sentences and using pictures, colors, shapes and different sizes in language learning could have significant influences on the process of second language learning especially for the young learners.

The findings also confirm Wu's (2008) claim that teaching English idioms with rich illustrations is one of the effective ways to teach idioms. He has proposed various effective activities for teaching English idioms and the use of pictures and visual art in learning idioms is one of them. It is believed that materials accompanied by visual constituents are likely to perpetuate the process of comprehension.

Besides, the findings run in parallel with the statements made by Lozanov, the originator of Suggestopedia, that art enables individuals to reach subconscious. He believes that art should be integrated as much as possible into the teaching process. Because the process of language learning has been occupied in the left hemisphere of the brain, however, the process of understanding and recognizing the world has been occupied in the right hemisphere of the brain and when there is a unity between conscious and subconscious levels, both the left and right hemisphere of the brain become activated and learning is enhanced. The findings of the study, in addition, is similar to Scarcella and Oxford (1992) who emphasize that teachers should illustrate key vocabulary effectively by showing pictures and diagrams so as to improve the ESL student's reading comprehension.

On the other hand, according to the result of the study, there was not a difference between females and males. Therefore, spatial intelligence seems not to be subject to sex difference and this similarity of the groups is too small to be taken into consideration. This finding is different from a study about a gender and spatial intelligence differences (Furnham, 2000). His research indicated that there are consistent sex differences in self-estimates of spatial intelligence. It showed that female self-estimates of spatial intelligence were lower than male self-estimates. The finding of the study, as well, is different with those of Halpern (1997) and Bennett (1996) in that they reported differences between males and females on spatial reasoning.

The findings of the study shed light to the significant role of the spatial intelligence in learning the English idioms. Accordingly, in the process of instructing the syllabus for the learners, everything that can be shown through the space, pictures, colors, shapes and sizes are called Spatial Intelligence-Based Instruction (SIBI). In fact, with regard to the significant effect of spatial intelligence-based instruction on learning pictorial idioms, it can be suggested that learners can learn English idioms easily if they are taught picture-based idiomatic expressions. In order to design and develop idioms-based syllabus and curriculum, the syllabus designers are supposed to pay close attention to the materials which can suit most of the learners and can attract the interests of the learners.

\section{References}

Armstrong, T. (2000). Multiple intelligences in the classroom (2nd edition). Association for Supervision and Curriculum Development.

Armstrong, T. (2003). The Multiple intelligences of reading and writing. Association for Supervision and Curriculum Development.

Armstrong, T. (2004).The best of multiple intelligences activities. Rachelle Cracchiolo, M.S. Ed.

Bennett, M. (1996). Men's and Women's Self-Estimates of Intelligence. The Journal of Social Psychology, 136, 411412.

Christison, M. A. (1999). Multiple Intelligences: theory and practice in adult ESL. Eric Digest. http://www.Cal. org/ncle /digest/MI.htm

Christison, M. A. and Kennedy, D. (1999). Multiple Intelligences: theory and practice in adult ESL. Eric Digest. http://www.Cal.org/ncle /digest/MI.htm

Cieslicka, A. (2006). Literal salience in on-line processing of language learners. Second Language Research, 22(2), 115-144.

Dillon, L. (2006). Multiple intelligence theory and the college English classroom. http://www.mcte.org/ journal / mej06/14.Dillon.pdf

Furnham, A. (2000). Thinking about intelligence. http://www.thepsychologist.org.uk/archive/archive_home .cfm/volumeID_13-editionID_49Article ID.../thepsychologist \%5Cfurnham.pdf 
Gardner, H. (1991). Intelligences in seven steps. http://www.newhorizons.org

Gardner, H. (1993). Frames of Mind: the theory of multiple intelligences. London: Fontana Press.

Gardner, H. (1999). Intelligences Reframed: multiple intelligences for the $21^{\text {st }}$ century. New York: Basic Books.

Gardner, H. (2006). The development and education of the mind. Great Britain: Routledge.

Halley, M. (2004). Learner-centered instruction and the theory of multiple intelligences with second language

learners. Teachers College Record, 106 (1), 163-180.

Halpern, D. (1997). Sex Differences in Intelligence. American Psychologist, 52, 1091-1102.

Hussein, R., Khanji, R., \& Makhzoomy, K. (2000). The acquisition of idioms: transfer or what? J. King Saud University, 12, 22-34.

Irujo, S. (1993). Steering clear: Avoidance in the production of idioms. International Review of Applied Linguistics, 21, 205-219.

Kallenbach, S., \& Veins, J. (2001). Multiple intelligences in practice: Teacher reports from the adult multiple intelligences study. ERIC/AE Digest Series.

McPartland, P. (1981). Take it Easy: American Idioms. Language Learning, 33(4), 5-10.

Nelson, E. (1992). Memory for metaphor by nonfluent bilinguals. Journal of Psycholinguistic Research 21, 111-25.

Nippold, M. A., \& Martin, S. T. (1989). Idiom interpretation in isolation versus context: A developmental study with adolescents. Journal of Speech and Hearing Research, 32, 59-66.

Saeidi, M. (2006). Multiple intelligence-based focus on forms: From Theory to Practice. Iran: Islamic Azad university of Tabriz.

Scarcella, R. C., \& Oxford, R. L. (1992). The tapestry of language learning: The individual in the communicative classroom. Boston: Heinle \& Heinle.

Wu, S. (2008).Effective activities for teaching English idioms to EFL learners. The Internet TESL Journal. http://iteslj.org/Techniques/Wu-TeachingIdioms.html. 